\title{
The predictive value of variables measurable in the ambulance and the development of the Predict Sepsis screening tools: a prospective cohort study
}

Ulrika Margareta Wallgren ${ }^{1,2} \mathbb{B}$, Jan Sjölin ${ }^{3}$, Hans Järnbert-Pettersson ${ }^{1}$ and Lisa Kurland ${ }^{1,4^{*}}$

\begin{abstract}
Background: Despite sepsis being a time critical condition with a high mortality, it is often not identified in a timely fashion. The aim of the current study was to create a screening tool based on bedside measurable variables predictive of sepsis among ambulance patients with infection according to clinical judgment by ambulance personnel.

Methods: Prospective cohort study of 551 adult patients presenting with suspected infection, performed in the ambulance setting of Stockholm during 2017-2018. 18 variables were measured in the ambulance (8 keywords related to medical history, 6 vital signs, 4 point-of-care blood tests, in addition to age, gender, and comorbidity. Logistic regression, area under the curve (AUC) and classification trees were used to study the association with sepsis. The AUC, sensitivity, specificity, predictive values and likelihood ratios were used to evaluate the predictive ability of sepsis screening models.

Results: The six variables with the strongest association with sepsis were: systolic blood pressure $\leq 100 \mathrm{mmHg}$, temperature $>38.5^{\circ} \mathrm{C}, \mathrm{GCS}<15$, lactate $>4 \mathrm{mmol} / \mathrm{L}$, gastrointestinal symptoms, and a history of acute altered mental status. These were combined into the Predict Sepsis screening tool 1, with a sensitivity of 0.90 , specificity 0.41 , AUC 0.77; 95\% confidence interval [CI] 0.73-0.81, PPV 0.52, and NPV 0.86. Combining a history of acute altered mental status with GCS $<15$ and excluding lactate in the Predict Sepsis screening tool 2 did not noticeably affect the AUC. In addition, the AUCS of these models did not differ noticeably when compared to a model including vital signs alone, with novel calculated cut-offs; the Predict Sepsis screening tool 3.

(Continued on next page)
\end{abstract}

\footnotetext{
* Correspondence: lisa.kurland@oru.se

'Karolinska Institutet, Department of Clinical Science and Education, Söderssjukhuset, Sjukhusbacken 10, 11883 Stockholm, Sweden

${ }^{4}$ Department of Medical Sciences, Örebro University, Campus USÖ, Södra Grev Rosengatan 32, 70112 Örebro, Sweden

Full list of author information is available at the end of the article
}

(c) The Author(s). 2020 Open Access This article is licensed under a Creative Commons Attribution 4.0 International License, which permits use, sharing, adaptation, distribution and reproduction in any medium or format, as long as you give appropriate credit to the original author(s) and the source, provide a link to the Creative Commons licence, and indicate if changes were made. The images or other third party material in this article are included in the article's Creative Commons licence, unless indicated otherwise in a credit line to the material. If material is not included in the article's Creative Commons licence and your intended use is not permitted by statutory regulation or exceeds the permitted use, you will need to obtain permission directly from the copyright holder. To view a copy of this licence, visit http://creativecommons.org/licenses/by/4.0/. The Creative Commons Public Domain Dedication waiver (http://creativecommons.org/publicdomain/zero/1.0/) applies to the data made available in this article, unless otherwise stated in a credit line to the data. 


\begin{abstract}
(Continued from previous page)
Conclusions: Systolic blood pressure $\leq 100 \mathrm{mmHg}$, temperature $>38.5^{\circ} \mathrm{C}, \mathrm{GCS}<15$, lactate $>4 \mathrm{mmol} / \mathrm{L}$, gastrointestinal symptoms, and a history of acute altered mental status demonstrated the strongest association with sepsis. We present three screening tools to predict sepsis with similar sensitivity. The results indicated no noticeable increase of predictive ability by including symptom-variables and blood tests to a sepsis screening tool in the current study population.
\end{abstract}

Trial registration: NCT03249597.

Keywords: Sepsis, Screening, Emergency medical services, Prehospital, Emergency care

\section{Background}

Sepsis is one of the most common medical emergencies and the mortality is high [1-3]. Despite sepsis being a time critical condition, it is often not identified in a timely fashion. Since time-to-treatment is related to patient outcome, early identification is necessary.

More than half of the patients with sepsis are transported to hospital by ambulance [4] and time to treatment is halved when the septic patient is identified by ambulance personnel [5]. Today, identification of the septic patient is based mainly on health care professionals using clinical judgment and this identification rate is inadequately low [6, 7]. Previous studies have demonstrated proof of principle that a screening tool increases the identification of septic patients in both the ambulance and the Emergency Department (ED) settings [6-9].

Existing screening tools are mainly based on vital signs and few are developed for use within the ambulance [8-10]. In addition to a complete lack of prospective studies, these screening tools have inherent problems since vital signs are normal in one third of ambulance patients with severe infections [11] which renders a different approach. We have in a previous study demonstrated that certain keywords related to patients' medical history recur in ambulance records of septic patients [12]. Eight keywords were particularly common with a prevalence exceeding $20 \%$. However, the specificity of these keywords with respect to sepsis has not yet been studied and information related to patients' medical history has not previously been included in sepsis screening tools. Additionally, no prior studies have demonstrated the added value of point-of-care (POC) blood tests for sepsis screening within ambulance care with the exception of lactate and glucose [10]. suPAR (soluble urokinase Plasminogen Activator Receptor) and HBP (heparin-binding protein) are two novel biomarkers for sepsis $[13,14]$ not previously studied in the ambulance.

We hypothesized that the identification of sepsis within ambulance care could be increased by combining keywords related to the patients' medical history and POC tests in addition to vital signs for sepsis screening. The aim of the current study was to create a screening tool based on bedside measurable variables predictive of sepsis among ambulance patients with infection according to clinical judgment by ambulance personnel. This is, to our knowledge, the first prospective study in the ambulance setting to study the association between symptoms, vital signs and POC tests and the outcome sepsis.

\section{Methods \\ Study design and setting}

The current study was a prospective cohort study in the ambulance setting of Stockholm performed between April 3rd, 2017 and August 30th, 2018. The study was performed Stockholm-county-wide, in collaboration with the ambulance provider Samariten Ambulans AB and all seven hospital bound EDs (Södersjukhuset, Karolinska Huddinge, Karolinska Solna, St Göran, Danderyd, Norrtälje, Södertälje) in Stockholm County Council. Samariten Ambulance $\mathrm{AB}$ is one of three ambulance providers in Stockholm, and accounts for 75,000 of approximately 183,000 annual ambulance assignments $[15,16]$. Ambulances are staffed with two nurse specialists or one nurse specialist and one emergency medical technician [16]. The population of Stockholm county is approximately 2.3 million [17] with approximately 480,000 annual visits to the EDs [18] in the Stockholm City County.

\section{Selection of study participants}

See Fig. 1 for flow chart of inclusion and exclusion.

\section{Inclusion criteria}

Inclusion criteria were adult ( $\geq 18$ years) non-trauma ambulance patients considered to suffer from a new onset infection (defined as symptoms that had begun within the last days) according to clinical judgment by the ambulance personnel.

All patients were enrolled by the ambulance personnel and transported to one of the above listed seven hospital bound EDs.

\section{Exclusion criteria}

Exclusion criteria were: 1) lack of written consent; 2) trauma other than falls at home; 3) patient leaving ED prior to physician assessment; 4) direct admission to 


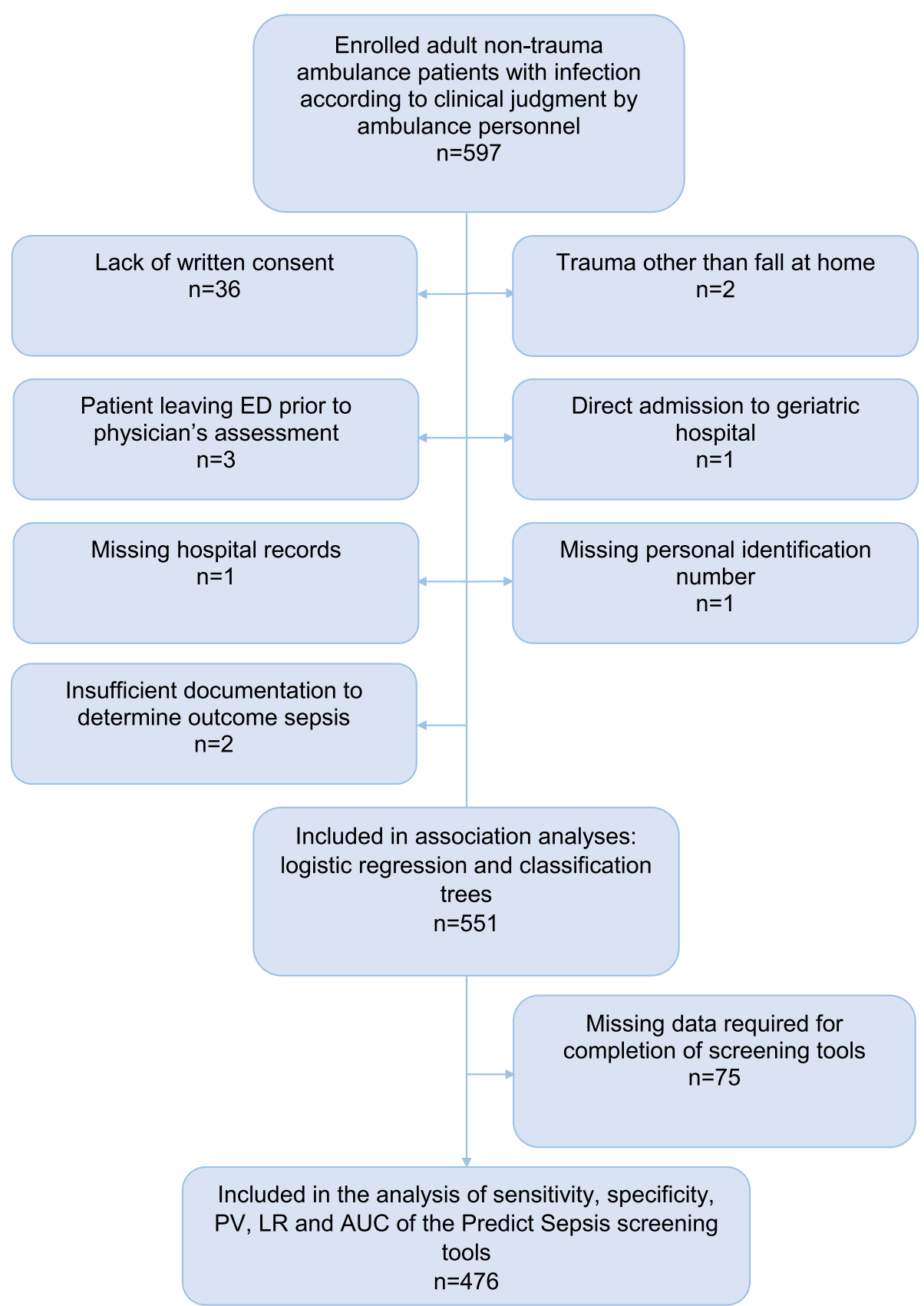

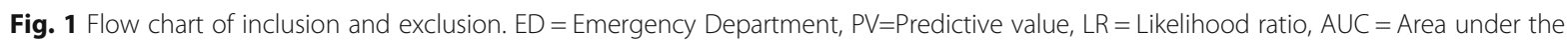
receiver operating curve

geriatric hospital i.e. bypassing an ED; 5) missing hospital records; 6) missing personal identification number; and 7) insufficient documentation to determine outcome sepsis.

\section{Study protocol}

A Case Report Form (CRF) including eight keywords related to medical history and six vital signs was used by the ambulance personnel. Vital signs not recorded in the
CRF were extracted from the ambulance records (amPHI ${ }^{\bullet}$ Prehospital ambulance record, Amphi Systems A/S, Aalborg, Denmark, and the digital IT-support for prehospital care in Stockholm; FRAPP ${ }^{\circ}$ (Framtida ITplattform för prehospital vård i Stockholms läns landsting).

Data related to ED arrival time, age, gender, preexisting comorbidity, criteria for suspicion of a newonset infection, in-hospital vital signs/ laboratory tests/ 
mortality and discharge International Classification of Diseases (ICD) code were retrieved from the hospital medical records (TakeCare ${ }^{\oplus}$, v. 18.3.10, CompuGroup Medical, Stockholm, Sweden).

\section{Predictive variables}

A total of 21 variables were measured, as follows:

\section{Keywords related to medical history}

Eight keywords related to medical history, with a previously demonstrated prevalence exceeding 20\% among septic patients in the ambulance based on results from a prior study [12], were registered in the ambulance. These keywords were: "fever or suspected fever", "pain", "acute altered mental status", "weakness of the legs", "breathing difficulties", "loss of energy", "gastrointestinal symptoms" and "risk factors for sepsis" [12], (see Table 1).

\section{Vital signs}

The first measured value in the ambulance of the six vital signs respiratory rate, oxygen saturation, heart rate, systolic blood pressure, Glasgow coma scale (GCS) and temperature were included.

\section{POC-tests}

Blood was drawn in the ambulance for four POC-tests; P-Glucose, P-Lactate, P-HBP and P-suPAR. For a detailed description of the handling and analyses of these POC-tests see Additional file 1.

\section{Demographic variables}

Age, gender, and data required for calculation of Charlson comorbidity score [19] were extracted from hospital records. Charlson comorbidity score is a validated method used to classify comorbid conditions which influence the risk of mortality and is developed for use in longitudinal studies [19].

\section{Outcomes}

The possible outcomes were sepsis or no sepsis, within the first $36 \mathrm{~h}$ after ED arrival.

\section{Sepsis}

Sepsis was defined as sepsis within $36 \mathrm{~h}$ from ED arrival, in accordance with the Sepsis-3 criteria [20]; i.e. infection (as defined in Additional file 2) in combination with an increased Sequential Organ Failure Assessment (SOFA) score of 2 points or more, as compared with the patient's preexisting status and based on review of the medical record. Septic shock was defined as vasopressor requirement and serum lactate level greater than 2 $\mathrm{mmol} / \mathrm{L}[20]$. The preexisting score was set to zero for patients with no previous recordings of variables needed for calculating the SOFA score [20]. Oxygen saturation level and level of oxygen supplied were converted to the partial pressure of oxygen $(\mathrm{PaO} 2) /$ fraction of inspired oxygen (FiO2) in accordance with Swedish Intensive care registry $[21,22]$.

\section{No sepsis}

Patients that did not fulfill sepsis criteria, as described above, were classified as "no sepsis".

\section{Calculation of sample size}

The current study was the first part of the larger Predict Sepsis study (NCT03249597). The sample size for the current study was originally based on 18 variables to be used in the logistic regression analysis which implied that 180 patients with sepsis were needed i.e. ten events for each predictor variable [23]. 20\% additional patients were included to compensate for missing data. Thus, the recruitment goal was set to include 216 patients with outcome sepsis (NCT03249597).

The prevalence of sepsis among ambulance patients was not previously known. Therefore, the first enrolled 315 patients were used to estimate the prevalence of sepsis in the study population and for the calculation of the final sample size.

\section{Data analysis}

Statistical analyses were performed using SPSS (Statistical Package for the Social Sciences) statistical software v. 23-25.0 (SPSS Inc., Chicago, IL, USA), and Clinical Research Calculators; Calculator 1, Vassarstats.net [24].

\section{Characteristics}

Normality distribution was assessed with the Kolmogorov-Smirnov and the Shapiro-Wilk tests and visually in histograms. Median and interquartile range (IQR) were used to describe age, vital signs and POC-test levels, since these variables were not normally distributed.

\section{Classification of variables in the regression analysis}

Keywords related to medical history Keywords were classified as present (yes)/ not present (no) in the regression analysis. Patients not able to answer yes or no were included in the yes-category for the association analyses since they were few (11-30 patients per keyword) and the prevalence of sepsis was similar.

Vital sign and POC-test categories Categories for numerical variables (vital signs and POC-tests) were calculated using a stepwise approach, including the following steps:

1) 8-10 categories were created for each numerical variable, including previously defined categories 
Table 1 Characteristics of the 551 ambulance patients with suspected infection ${ }^{\text {a }}$

\begin{tabular}{|c|c|}
\hline Variable & $\begin{array}{l}\text { Number }{ }^{\mathrm{b}}\left(\%^{\mathrm{b}}\right) \\
N=551\end{array}$ \\
\hline \multicolumn{2}{|l|}{ Age (yr) } \\
\hline \multicolumn{2}{|l|}{ Gender } \\
\hline -male & $331 / 551(60.1)$ \\
\hline \multicolumn{2}{|l|}{ Ambulance parameters } \\
\hline \multicolumn{2}{|l|}{ Prio } \\
\hline 1 & $100 / 545(18.3)$ \\
\hline 2 & $384 / 545(70.5)$ \\
\hline 3 & $61 / 545(11.2)$ \\
\hline \multicolumn{2}{|l|}{ Prevalence of keywords related to medical history ${ }^{c}$} \\
\hline 1. Fever or suspected fever & 403/551 (73.1) \\
\hline 2. Pain & $256 / 550(46.5)$ \\
\hline 3. Acute altered mental status & $328 / 551(59.5)$ \\
\hline 4. Weakness of the legs (difficulties to walk/stand/raise/fallen/found on the floor or similar) & $419 / 551(76.0)$ \\
\hline 5. Breathing difficulties & 280/549 (51.0) \\
\hline 6. Loss of energy & $490 / 551(88.9)$ \\
\hline 7. Gastrointestinal symptoms (vomiting/diarrhoea) & $188 / 550(34.2)$ \\
\hline 8. Risk factors for sepsis ${ }^{d}$ & 229/549 (41.7) \\
\hline
\end{tabular}

\title{
Vital signs
}

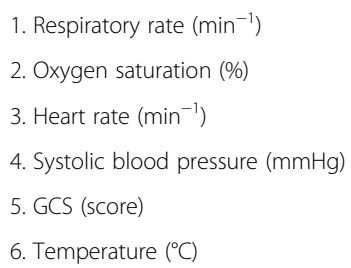

\section{POC-tests}

$$
\begin{aligned}
& \text { 1. P-Glucose }(\mathrm{mmol} / \mathrm{L}) \\
& \text { 2. P-Lactate }(\mathrm{mmol} / \mathrm{L}) \\
& \text { 3. P-suPAR }(\mathrm{ng} / \mathrm{mL}) \\
& \text { 4. P-HBP }(\mathrm{ng} / \mathrm{mL})
\end{aligned}
$$

\section{Comorbidity}

Charlson comorbidity score

\section{Admitted to in-hospital care}

454/551 (82.4)

\section{Outcome}

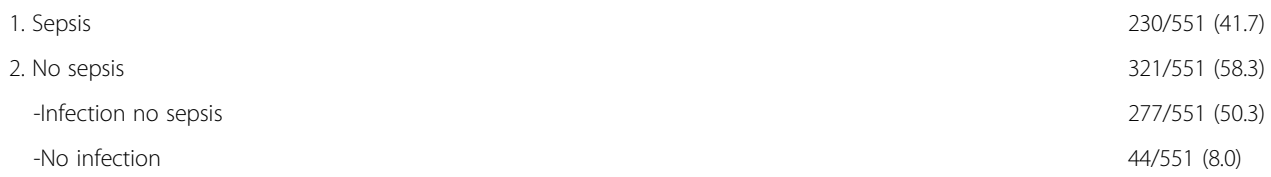

1. Sepsis

230/551 (41.7)

2. No sepsis

$321 / 551(58.3)$

-Infection no sepsis

$277 / 551(50.3)$

-No infection

$44 / 551(8.0)$

\section{ICD-code upon hospital discharge}

\author{
ICD-code sepsis \\ $54 / 549(9.8)$ \\ ICD-code infection \\ $358 / 549(65.2)$ \\ In-hospital mortality \\ $33 / 551(6.0)$
}

IQR Interquartile range, GCS Glasgow Coma Scale, POC Point Of Care, suPAR soluble urokinase Plasminogen Activating Receptor, HBP Heparin Binding Protein, ED Emergency Department, qSOFA quick SOFA (Sequential Organ Failure Assessment score), ICD International Statistical Classification of Diseases and Related Health Problems ${ }^{a} 551$ adult ambulance patients with infection according to clinical judgment by ambulance personnel and documentation to determine if the patient had outcome sepsis according to Sepsis-3 or not

${ }^{b}$ Of patients with documented variable

'All symptoms were new-onset or increased compared to the patient's habitual state

${ }^{d}$ such as infection/antibiotic treatment/chemotherapy/ surgical or urological procedure/new blood-/urinary catheters last weeks or alcohol/drug abuse 
according to NEWS [25], SIRS [26], Robson [10] when possible, and aiming for equal ranges for each created category.

2) The 8-10 categories from step 1 were merged into 3-4 categories for each variable, based on odds ratios, with the aim to not overlap the $95 \%$ confidence intervals and that the prevalence of sepsis was similar in the merged categories.

3) The 3-4 categories from step 2 were merged into the final 2-3 categories using the same criteria as above described in step 2 .

Comparisons of receiver operating characteristic (ROC) curves and AUC values for the continuous variable and their three categorized versions $(8-10$ categories, 3-4 categories and 2-3 categories for each numerical variable) were performed for each step in order to assess that the categorization had not caused an inacceptable loss of information.

Underlying data describing the prevalence of sepsis within categories is described in Additional file 3.

\section{Determination of predictors of sepsis among patients with infection in the ambulance according to clinical judgment by ambulance personnel}

Logistic regression Identification of predictor variables for sepsis was performed as follows: first an unadjusted univariable (crude) analysis was performed for each of the 21 variables. AUC values were calculated for all variables that showed a significant association $(p<0.05)$ with sepsis. Second, a multivariable adjusted logistic regression was performed including variables which were significantly associated with outcome sepsis in the univariable analysis. Odds ratios (ORs) were reported with corresponding $95 \%$ confidence intervals.

Classification trees Classification trees were used as a complement to logistic regression to identify variables associated with sepsis and to stratify groups of patients according to risk of sepsis. An advantage of this method as compared to logistic regression is that interactions between variables can be discovered and visualized. The Chi-squared automatic interaction detection (CHAID) algorithm was used to build the trees [27] and starts with all data in one group. Each possible split for each variable is considered in order to find the split that leads to the strongest association with the outcome: i.e. sepsis (yes/no). The analysis was based on the 21 variables described above. The resulting groups were split until one of the following stop criteria was reached: tree depth was limited to five levels, a group with less than 25 patients was formed or a split with a Bonferroni adjustment of less than 0.05 was executed.

\section{Models used to predict sepsis}

Models for sepsis screening were created based on significant association with sepsis in univariable and multivariable regression analyses, in addition to significant association in univariable analysis in combination with significant $p$-values $(<0.05)$ for the AUC of the variable.

There was a trade-off between the number of variables included in the model and the contribution to prediction of the outcome sepsis. The objective to include a small number of variables rather than a larger is based on the assumption that the screening tool is a clinical bedside tool vs an electronically embedded tool. As a final step, models combining the keyword acute altered mental status and GCS $<15$ and, additionally, models excluding lactate were tested. This was done to evaluate, by ROC curves, how reduction of variables and avoidance of an invasive step (lactate measurement) affected the predictive ability with respect to sepsis identification.

The predictive models were evaluated based on scores for individual variables instead of the estimated regression scores, as follows. First, each individual variable in the model was scored based on the strength of the association with sepsis in regression analyses and classification trees. Secondly, cut-offs for total scores were evaluated with respect to sensitivity and specificity for sepsis by applying ROC curves. A comparison of the predictive ability for each model, given a specific cut-off for total score, was performed by calculating AUC (according to SPSS), sensitivity, specificity, positive predictive value (PPV), negative predictive value (NPV) and likelihood ratios (LRs) (according to Vassarstat.net [24]).

\section{Ethical approval and compliance with international standards of study procedures}

The study received approval from the Stockholm Regional Ethical Review Board (reference number 2016/ 2001-31/2 and 2018/2202). Written consent was obtained from all participants.

This study complied with the Declaration of Helsinki [28] and the manuscript was drafted according to the Standards for the Reporting of Diagnostic accuracy studies (STARD) criteria [29].

\section{Results}

\section{Patient characteristics}

See flow chart for inclusion and exclusion in Fig. 1.

553 patients with suspected infection in the ambulance were included. Of these, $454(82.4 \%)$ were admitted to in-hospital care. A total of 551 patients had sufficient documentation to determine whether the patient had outcome sepsis or not within $36 \mathrm{~h}$ from ED arrival and were accordingly included in the regression and classification tree analyses. Patient characteristics are presented in Table 1. 
Of the 551 included patients 331 (60.1\%) were men, the median age was 78 years (IQR 71-85) and 230 (41.7\%) had sepsis, see Table 1 . Of the 230 patients with sepsis, 23 patients (10\%) died during in-hospital care. Forty-four of 228 patients (19.3\%) with sepsis in accordance with the Sepsis-3 criteria [20], and a documented ICD-code upon hospital discharge, had an ICD-code consistent with sepsis.

\section{Predictors of sepsis \\ Logistic regression analysis}

Individual ROC curves for the 17 variables that showed a significant association with sepsis in the univariable analysis are presented in Additional file 4.

Keywords related to medical history The keywords with the strongest association with sepsis were acute altered mental status and gastrointestinal symptoms, see Table 2.

Vital signs The calculated vital sign and POC-test level categories used in the regression analyses are presented in Table 2. The vital signs with the strongest association with sepsis were systolic blood pressure $\leq 100 \mathrm{mmHg}$, GCS $<15$, and temperature $>38.5^{\circ} \mathrm{C}$, see Table 2 . Heart rate demonstrated the weakest association with sepsis.

POC-tests All POC-tests except for P-Glucose had a significant association with sepsis in the univariable logistic regression. The only POC-test that remained significantly associated with sepsis in the multivariable analysis was P-Lactate $>4 \mathrm{mmol} / \mathrm{L}$, see Table 2 .

Demographic variables A Charlson comorbidity score of $\geq 5$ points was significantly associated with outcome sepsis in univariable analysis. This association did not remain significant after adjusting for all other variables, see Table 2 .

\section{Classification trees}

The vital signs GCS and temperature were most strongly associated with sepsis according to classification tree analyses, as shown in Fig. 2.

\section{Models and the Predict Sepsis screening tools}

ROC curves for models based on variable groups (symptoms, vital signs and POC-tests) and combinations thereof are illustrated in Fig. 3. Vital signs were, as a variable group, the strongest predictors of sepsis (Fig. 3).

A description of the variables included in the models and the method used to develop each model is presented in Additional file 5. Scores for individual variables in the tools, and total scores for the models, considered positive for suspected sepsis, were chosen based on comparisons of AUC values, see Table 3 and Fig. 4.

The variables demonstrating the strongest association with sepsis according to logistic regression and classification trees were acute altered mental status, gastrointestinal symptoms, systolic blood pressure $\leq 100$ $\mathrm{mmHg}, \mathrm{GCS}<15$, temperature $>38.5^{\circ} \mathrm{C}$ and P-Lactate $>4 \mathrm{mmol} / \mathrm{L}$. These variables were combined into the "Predict Sepsis screening tool 1", see Table 3 and Fig. 4.

The AUC was not reduced noticeably when a combined variable for a decreased level of consciousness (a history of acute altered mental status and/or GCS <15) was introduced and P-Lactate was excluded in the Predict Sepsis screening tool 2, based on 4 variables (see Table 3 and Fig. 4).

The Predict Sepsis screening tool 3 was based on the 6 vital signs significantly associated with sepsis in univariable analysis, applying the novel calculated categories for each vital sign (see Table 3 and Fig. 4).

The Predict Sepsis screening tool 1, 2 and 3 identified the same septic patients to a large extent; 163 patients were identified by all three tools, eight patients were identified by tool 1 and 2 but not by tool 3, eight patients were identified by tool 1 and 3 but not by tool 2, one patient was identified solely by tool 1 and nine septic patients were not identified by either tool.

For AUCs of the Predict Sepsis screening tools before and after introduction of scores, see Additional file 5 and Table 3. The sensitivity, specificity, predictive values and likelihood ratios for the Predict Sepsis screening tools are presented in Table 3 .

\section{Discussion}

This is the first prospective study in the ambulance setting to study the association between variables measurable in the ambulance and the outcome sepsis. It is also the first study to include symptom-variables in a sepsis screening tool. Systolic blood pressure $\leq 100 \mathrm{mmHg}$, temperature $>38.5^{\circ} \mathrm{C}, \mathrm{GCS}<15, \mathrm{P}$-Lactate $>4 \mathrm{mmol} / \mathrm{L}$, gastrointestinal symptoms, and a history of acute altered mental status demonstrated the strongest association with sepsis. I.e. two symptoms and one POC-test were significantly associated with outcome sepsis in the multivariable analysis. However, interestingly, vital signs were, as a variable group, the strongest predictors of sepsis.

The Predict Sepsis screening tool 1 and 2 both include symptom-variables. The second tool is based on only four variables, which makes it feasible to use as a handson screening tool without the need of incorporation in electronic systems. However, the predictive ability of the Predict Sepsis screening tool 1 and 2 was similar to that of the Predict Sepsis screening tool 3, which was built on vital signs alone, but with new calculated cut-offs for each included vital sign. This implies that addition of 
Table 2 Association between 21 variables and sepsis ${ }^{\mathrm{a}}$ among $551^{\mathrm{b}}$ ambulance patients with suspected infection

\begin{tabular}{|c|c|c|c|c|c|c|c|c|c|}
\hline \multirow[t]{3}{*}{ Variable } & \multirow[t]{3}{*}{ Category } & \multirow{2}{*}{\multicolumn{2}{|c|}{$\begin{array}{l}\text { Crude } \\
n=551\end{array}$}} & \multicolumn{3}{|c|}{ Univariable, unadjusted } & \multirow{2}{*}{\multicolumn{3}{|c|}{$\begin{array}{l}\text { Multivariable, adjusted } \\
\text { Adjusted for all factors that were significant } \\
\text { in the univariable analysis, } n=484\end{array}$}} \\
\hline & & & & \multirow[t]{2}{*}{$P$-value } & \multicolumn{2}{|c|}{$n=551$} & & & \\
\hline & & $\overline{n^{c}}$ & $\%$ sepsis & & $\overline{\mathrm{OR}}$ & $95 \% \mathrm{Cl}$ & $P$-value & OR & $95 \% \mathrm{Cl}$ \\
\hline \multicolumn{10}{|l|}{ Keywords related to medical history } \\
\hline \multirow[t]{2}{*}{ Fever or suspected fever } & yes $^{d}$ & 417 & 45.1 & 0.005 & 1.8 & $1.2-2.7$ & 0.98 & 1.0 & $0.6-1.7$ \\
\hline & no & 134 & 31.3 & Ref & Ref & Ref & - & Ref & - \\
\hline \multirow[t]{2}{*}{ Pain } & yes $^{d}$ & 277 & 43.0 & 0.53 & 1.1 & $0.8-1.6$ & - & - & - \\
\hline & no & 273 & 40.3 & Ref & Ref & Ref & - & Ref & - \\
\hline \multirow[t]{2}{*}{ Acute altered mental status } & yes $^{d}$ & 344 & 49.4 & $<0.001$ & 2.4 & $1.7-3.5$ & 0.03 & 1.8 & $1.1-2.9$ \\
\hline & no & 207 & 29.0 & Ref & Ref & Ref & - & Ref & - \\
\hline \multirow[t]{2}{*}{ Weakness of the legs } & yes $^{d}$ & 442 & 44.6 & 0.007 & 1.9 & $1.2-2.9$ & 0.61 & 1.2 & $0.6-2.1$ \\
\hline & no & 109 & 30.3 & Ref & Ref & Ref & - & Ref & - \\
\hline \multirow[t]{2}{*}{ Breathing difficulties } & yes $^{d}$ & 299 & 48.2 & 0.001 & 1.8 & $1.3-2.6$ & 0.24 & 1.3 & $0.8-2.2$ \\
\hline & no & 250 & 34.0 & Ref & Ref & Ref & - & Ref & - \\
\hline \multirow[t]{2}{*}{ Loss of energy } & yes $^{d}$ & 501 & 43.1 & 0.04 & 2.0 & $1.0-3.7$ & 0.79 & 1.1 & $0.5-2.6$ \\
\hline & no & 50 & 28.0 & Ref & Ref & Ref & - & Ref & - \\
\hline \multirow[t]{2}{*}{ Gastrointestinal symptoms } & yes $^{d}$ & 214 & 52.8 & $<0.001$ & 2.1 & $1.5-2.3 .0$ & 0.006 & 1.9 & $1.2-2.9$ \\
\hline & no & 336 & 34.8 & Ref & Ref & Ref & - & Ref & - \\
\hline \multirow[t]{2}{*}{ Risk factors for sepsis } & yes $^{d}$ & 256 & 47.7 & 0.008 & 1.6 & $1.1-2.2$ & 0.46 & 1.2 & $0.8-1.9$ \\
\hline & no & 293 & 36.5 & Ref & Ref & Ref & - & Ref & - \\
\hline \multicolumn{10}{|l|}{ Vital signs } \\
\hline \multirow[t]{2}{*}{ Respiratory rate $>24$ breaths/min } & yes & 189 & 56.1 & $<0.001$ & 2.4 & $1.7-3.5$ & 0.53 & 1.2 & $0.7-2.0$ \\
\hline & no & 361 & 34.3 & Ref & Ref & Ref & - & Ref & - \\
\hline \multirow[t]{2}{*}{ Oxygen saturation $<94 \%$} & yes & 232 & 55.6 & $<0.001$ & 2.8 & $1.9-3.9$ & 0.08 & 1.6 & $1.0-2.5$ \\
\hline & no & 319 & 31.2 & Ref & Ref & Ref & - & Ref & - \\
\hline \multirow[t]{2}{*}{ Heart rate $>110$ beats $/ \mathrm{min}$} & yes & 106 & 58.1 & $<0.001$ & 2.3 & $1.5-3.5$ & 0.09 & 1.6 & $0.9-2.8$ \\
\hline & no & 446 & 37.8 & Ref & Ref & Ref & - & Ref & - \\
\hline \multirow[t]{2}{*}{ Systolic blood pressure $\leq 100 \mathrm{mmHg}$} & yes & 54 & 68.5 & $<0.001$ & 3.4 & $1.9-6.3$ & 0.001 & 3.6 & $1.7-7.6$ \\
\hline & no & 496 & 38.7 & Ref & Ref & Ref & - & Ref & - \\
\hline \multirow[t]{2}{*}{ Level of consciousness, GCS $<15$} & yes & 115 & 67.0 & $<0.001$ & 3.8 & $2.4-5.8$ & $<0.001$ & 3.5 & $2.0-6.2$ \\
\hline & no & 416 & 35.0 & Ref & Ref & Ref & - & Ref & - \\
\hline Temperature, ${ }^{\circ} \mathrm{C}$ & & & & & & & $<0.001$ & & \\
\hline$\leq 38.0$ & yes & 235 & 27.0 & Ref & Ref & Ref & - & Ref & - \\
\hline $38.1-38.5$ & yes & 91 & 41.8 & 0.01 & 1.9 & $1.2-3.2$ & 0.02 & 2.2 & $1.1-4.2$ \\
\hline$>38.5$ & yes & 223 & 56.1 & $<0.001$ & 3.4 & $2.3-5.1$ & $<0.001$ & 3.3 & $2.0-5.6$ \\
\hline POC-tests & & & & & & & & & \\
\hline P-Glucose $>6.5 \mathrm{mmol} / \mathrm{L}$ & yes & 410 & 42.7 & 0.10 & 1.5 & $0.9-2.3$ & - & - & - \\
\hline & no & 105 & 33.7 & Ref & Ref & Ref & - & Ref & - \\
\hline P-Lactate, mmol/L & & & & & & & 0.08 & & - \\
\hline$\leq 2.0$ & yes & 340 & 36.1 & Ref & Ref & Ref & - & Ref & \\
\hline $2.1-4.0$ & yes & 160 & 46.3 & 0.03 & 1.5 & $1.0-2.2$ & 0.35 & 1.3 & $0.8-2.1$ \\
\hline$>4.0$ & yes & 38 & 76.3 & $<0.001$ & 5.7 & $2.6-12.4$ & 0.03 & 2.8 & $1.1-7.3$ \\
\hline P-suPAR, ng/mL & & & & & & & 0.31 & & \\
\hline$<4.0$ & yes & 184 & 30.4 & Ref & Ref & Ref & - & Ref & - \\
\hline $4.0-7.99$ & yes & 263 & 41.4 & 0.02 & 1.6 & $1.1-2.4$ & 0.41 & 1.2 & $0.8-2.0$ \\
\hline
\end{tabular}


Table 2 Association between 21 variables and sepsis among $551^{\mathrm{b}}$ ambulance patients with suspected infection (Continued)

\begin{tabular}{|c|c|c|c|c|c|c|c|c|c|}
\hline \multirow[t]{3}{*}{ Variable } & \multirow[t]{3}{*}{ Category } & \multirow{2}{*}{\multicolumn{2}{|c|}{$\begin{array}{l}\text { Crude } \\
n=551\end{array}$}} & \multicolumn{3}{|c|}{ Univariable, unadjusted } & \multirow{2}{*}{\multicolumn{3}{|c|}{$\begin{array}{l}\text { Multivariable, adjusted } \\
\text { Adjusted for all factors that were significant } \\
\text { in the univariable analysis, } n=484\end{array}$}} \\
\hline & & & & \multirow[t]{2}{*}{$P$-value } & \multicolumn{2}{|c|}{$n=551$} & & & \\
\hline & & $\overline{n^{c}}$ & $\%$ sepsis & & $\overline{\mathrm{OR}}$ & $95 \% \mathrm{Cl}$ & $P$-value & OR & $95 \% \mathrm{Cl}$ \\
\hline$\geq 8.0$ & yes & 93 & 64.5 & $<0.001$ & 4.2 & $2.4-7.1$ & 0.13 & 1.7 & $0.9-3.4$ \\
\hline \multirow[t]{2}{*}{$\mathrm{P}-\mathrm{HBP} \geq 15.0 \mathrm{ng} / \mathrm{mL}$} & yes & 235 & 52.8 & $<0.001$ & 2.3 & $1.6-3.2$ & 0.37 & 1.2 & $0.8-2.0$ \\
\hline & no & 290 & 33.1 & Ref & Ref & Ref & - & Ref & - \\
\hline \multicolumn{10}{|l|}{ Demographic variables } \\
\hline \multirow[t]{2}{*}{ Age $\geq 65$ years } & yes & 474 & 41.6 & 0.83 & 0.9 & $0.6-1.5$ & - & - & - \\
\hline & no & 77 & 42.9 & Ref & Ref & Ref & - & Ref & - \\
\hline \multirow[t]{2}{*}{ Gender, male } & yes & 331 & 43.8 & 0.23 & 1.2 & $0.9-1.8$ & - & - & - \\
\hline & no & 220 & 38.6 & Ref & Ref & Ref & - & Ref & - \\
\hline \multirow[t]{2}{*}{ Charlson comorbidity score $\geq 5$ points } & yes & 86 & 55.8 & 0.004 & 2.0 & $1.2-3.1$ & 0.13 & 1.6 & $0.9-3.1$ \\
\hline & no & 465 & 39.1 & Ref & Ref & Ref & - & Ref & - \\
\hline
\end{tabular}

OR Odds Ratio, Cl Confidence Interval, Ref Reference, GCS Glasgow Coma Scale, suPAR soluble urokinase Plasminogen Activating Receptor, HBP Heparin Binding Protein

a Sepsis is defined in accordance with Sepsis-3 as a) infection $+\geq 2$ SOFA criteria, or b) infection + vasopressor need and lactate $>2$ (septic shock)

${ }^{b}$ Of total 553 patients with infection according to clinical judgment by ambulance personnel, 551 patients had the required documentation to determine whether the patient had sepsis or not. These 551 patients were included in the regression analysis

cof patients with documentation of the variable

'Patients that were not able to answer yes or no were included in the yes-category in the logistic regression and classification tree analyses (11-30 patients/ keyword), based on similarity in prevalence of sepsis and overlapping Cls in these groups

Significant $P$-values are bolded

symptom-variables and POC-tests did not noticeably increase the predictive ability of a sepsis screening tool in the current study population.

It is, in our opinion, the clinical setting where the tool is going to be implemented that is the determining factor for which tool to recommend, since the predictive ability of these three tools was similar.

\section{Predictors of sepsis}

Keywords reflecting gastrointestinal symptoms and acute altered mental status demonstrated a stronger association with sepsis than "classic" symptoms of sepsis such as a history of fever. This finding is novel and indicates that these symptoms require more attention.

Systolic blood pressure, GCS and temperature were the vital signs that demonstrated the strongest association with sepsis. However, one third of the septic patient presented with a normal systolic blood pressure, two thirds had a normal GCS and one third lacked fever. This is consistent with a previous study by Suffoletto et al [11], demonstrating that more than one third of the patients with severe infections present with normal vital signs to the ambulance.

P-Lactate was the POC-test that demonstrated the strongest association with sepsis and was included in some of the models. However, excluding P-Lactate in the Predict Sepsis screening tool 2 did not noticeably decrease the predictive ability. This raises the question if the benefit of a slightly higher AUC in a screening tool is worth the disadvantages of a clinically invasive step, i.e. a blood test. A previous study by Singer et al. demonstrated a moderate to good specificity but a low sensitivity for POC lactate in adult ED patients with suspected sepsis [30], and Moran et al. stated that the lactate-added value is dependent on the underlying predictive model [31].

Age has been shown to be a predictor of sepsis among ambulance patients [9]. This was however not confirmed in the current study, which could be explained by the median age being similar in the two outcome groups i.e. sepsis and no sepsis.

\section{Models and comparison of screening tools}

All the calculated models demonstrated good AUC values. The inclusion of fewer variables in the models did not noticeably affect the AUC. This is valuable information since the ambulance setting constitutes an environment where every minute counts and using fewer variables should save time, i.e. unless the screening tool can be included in an electronic decision support system. If a screening tool is incorporated in an electronic system, the number of included variables is of less importance. Hence, which tool is the optimal tool will depend on how the tool is planned to be implemented within clinical practice, i.e. as a hands-on screening tool or as an electronic decision support tool.

It is a challenge to develop a tool combining a high sensitivity with a high specificity. The low specificity of both the Predict Sepsis screening tools and preexisting screening tools $[8,10]$ is troublesome since it may cause 


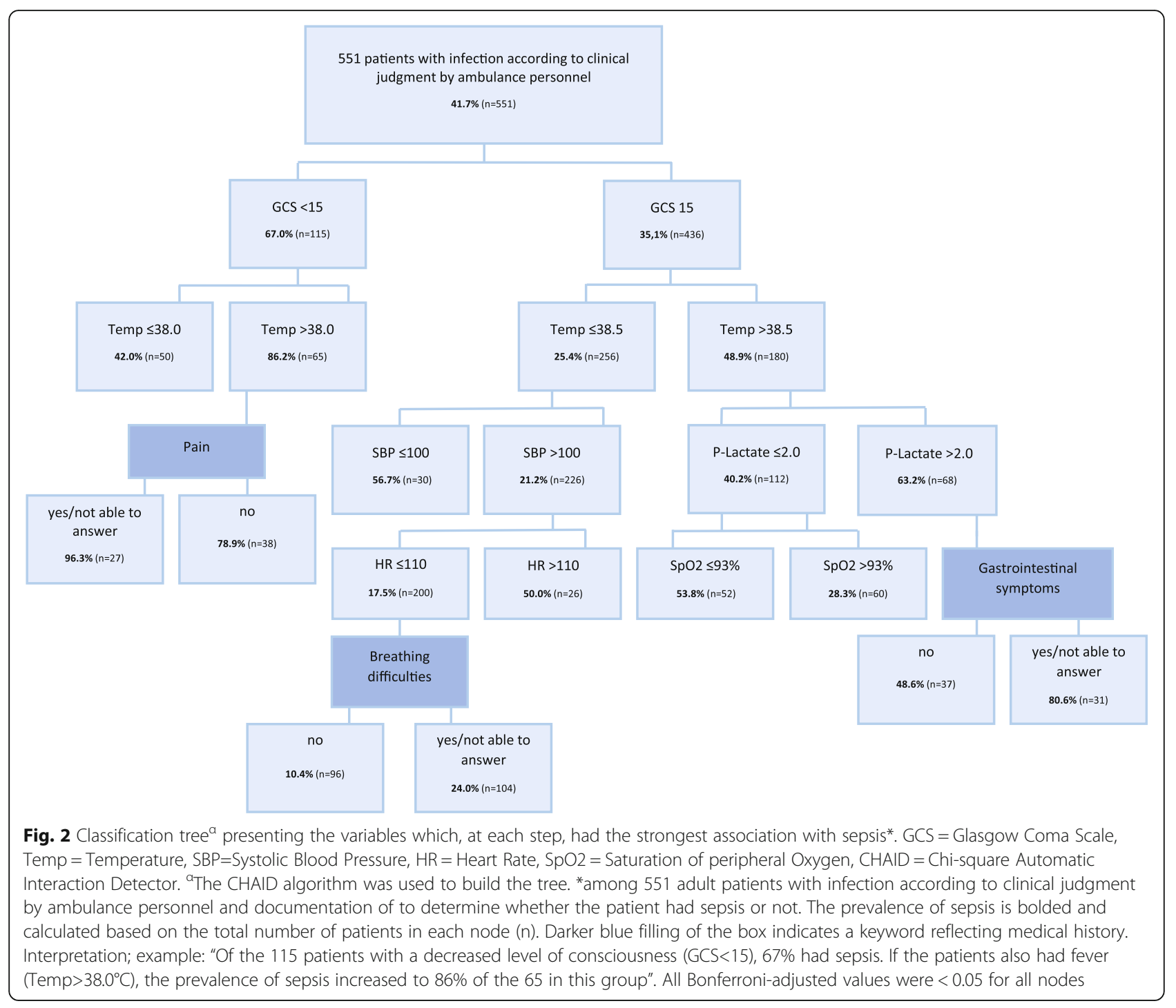

false sepsis alerts. However, we considered a high sensitivity to be more important since the major clinical problem is not identifying the septic patient in a timely fashion [5, 6, 32]. Some of the difficulties in combining a high sensitivity with a high specificity could be explained by the heterogenous presentations of sepsis. Sepsis is likely not to be one but rather several conditions influenced by both microbial and host factors, which may contribute to the heterogenicity with respect to presentation. This line of reasoning is supported by Seymour et al., describing several phenotypes of sepsis [33].

\section{Clinical implementation of the Predict Sepsis screening tools}

The objective of the application of a screening tool in the ambulance is to increase the identification of septic patients and enable timely treatment. Previous studies have shown that time to treatment is halved when the septic patient is identified by ambulance personnel [5] underscoring the importance of identification of the septic patient in the ambulance.

The Predict Sepsis screening tool 1 includes lactate measurement, which is not implemented in all ambulance settings. P-Lactate $>4 \mathrm{mmol} / \mathrm{L}$ was one of the variables that remained significantly associated with sepsis in the multivariable logistic regression analysis. However, the predictive ability of the models including lactate was not superior to that of the models excluding this invasive step. Hence, we do not consider lactate measurement justifiable as it may cause a delay of the sepsis screening and the transport of the patient in addition to discomfort from the patient's perspective.

Predict Sepsis screening tool 2 is based on four variables of which two are vital signs and two symptombased variables. This makes the Predict Sepsis screening tool 2 feasible to use as a hands-on screening tool in an 


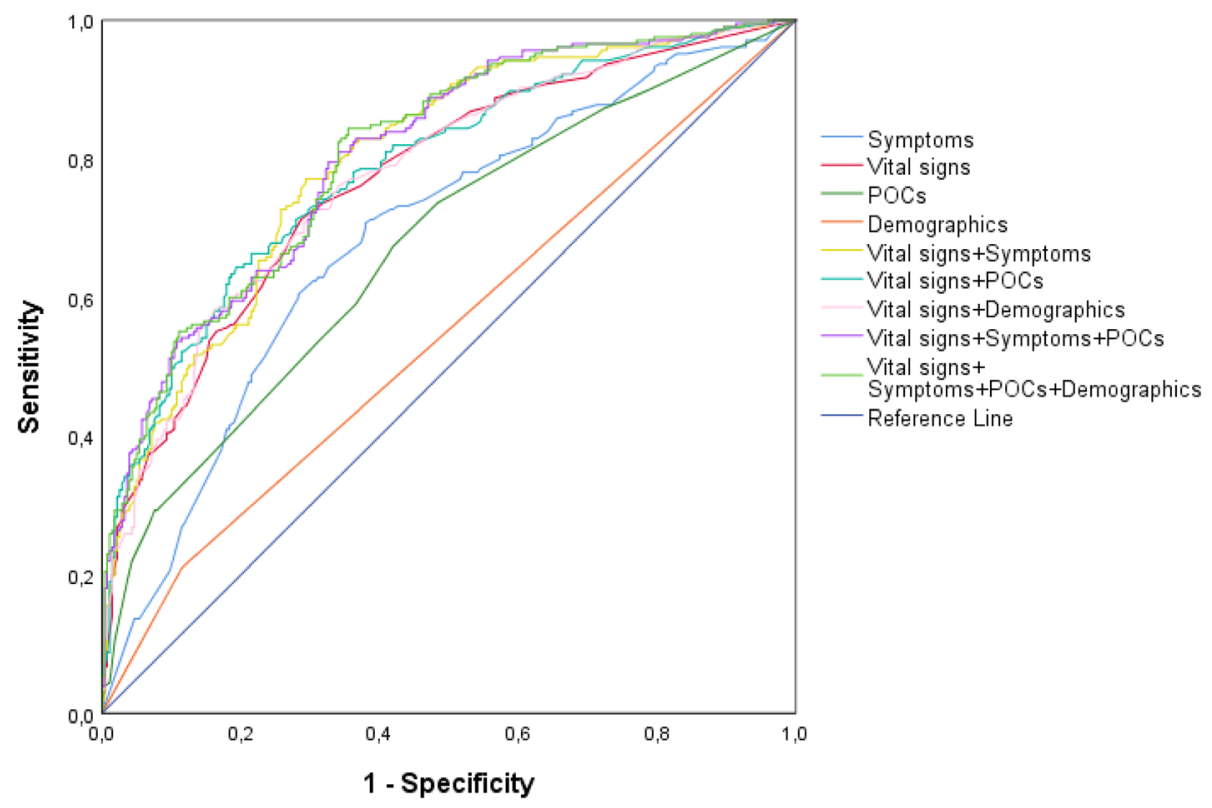

Fig. 3 ROC curves for models based on variable groups and combinations of these. ROC $=$ Receiver Operating Characteristic, POCs $=$ point-of-care blood tests. Only variables significantly associated with sepsis in the univariable analysis are included in the models

ambulance setting without a computer-based alert system. However, implementation of the Predict Sepsis screening tool 2 requires the ambulance personnel to ask all patients with clinically suspected infection whether they have gastrointestinal symptoms or not. Since this request is not part of standard procedure, it could be considered a disadvantage.

Predict Sepsis screening tool 3 is based on six vital signs alone. The advantage of this tool is that vital signs are routinely measured within ambulance care. It is however noteworthy that the cut-offs for each vital sign were calculated in the current study and not those typically applied today as clinical routine. The application of Predict Sepsis screening tool 3 is particularly feasible in settings with computer-based alert systems, although the tool may also be used manually.

\section{Strengths and limitations of the current study}

The strengths of the current study were the prospective design, the novel concept to include keywords related to medical history and POCs in the analyses, in addition to vital signs, and to apply calculated cut-offs for vital signs and POC-tests rather than using previously published cut-off levels. Patients with clinically suspected infection are common in the ambulance and it is of importance to identify those at risk of developing a severe infection such as sepsis. In addition, patients with a decreased level of consciousness were included in the current study, reducing selection bias.

There are several limitations to the current study. The categorization of vital signs and POC-tests could be questioned. However, the categorized variables followed the ROC curves for the continuous variables to a large extent, supporting well-chosen cut-off levels.

The definition of infection could be criticized. The Sepsis- 1 and -2 consensus documents $[26,34]$ defined infection as "a pathological process caused by invasion of normally sterile tissue/fluid or body cavity by pathogenic or potentially pathogenic micro-organisms". Neither does Sepsis-3 include a detailed definition of infection [20], nor are there other consensus criteria for infection. The definition of infection used in the current study is based on clinical experience and symptoms frequently reported by patients suffering from infection and has been used in prior publications $[6,7,12]$. The ability of ambulance personnel to identify patients with infection was high in the current study; $92 \%$ of the patients with suspected infection according to clinical judgment by ambulance personnel fulfilled the predefined criteria for infection. We consider it an advantage to have used stringent criteria for the definition of infection despite potential shortcomings of this specific definition.

Furthermore, there is an inherent risk that the predictive ability of a screening tool is higher in the population in which it is was developed than in other populations. Hence, the Predict Sepsis screening tools need to be externally validated.

Finally, the results are limited to the specific population of ambulance patients with suspected infection, rendering generalization of the results to the population of all patients presenting to the ambulance as not correct. It would be of interest to study the potential benefit of 


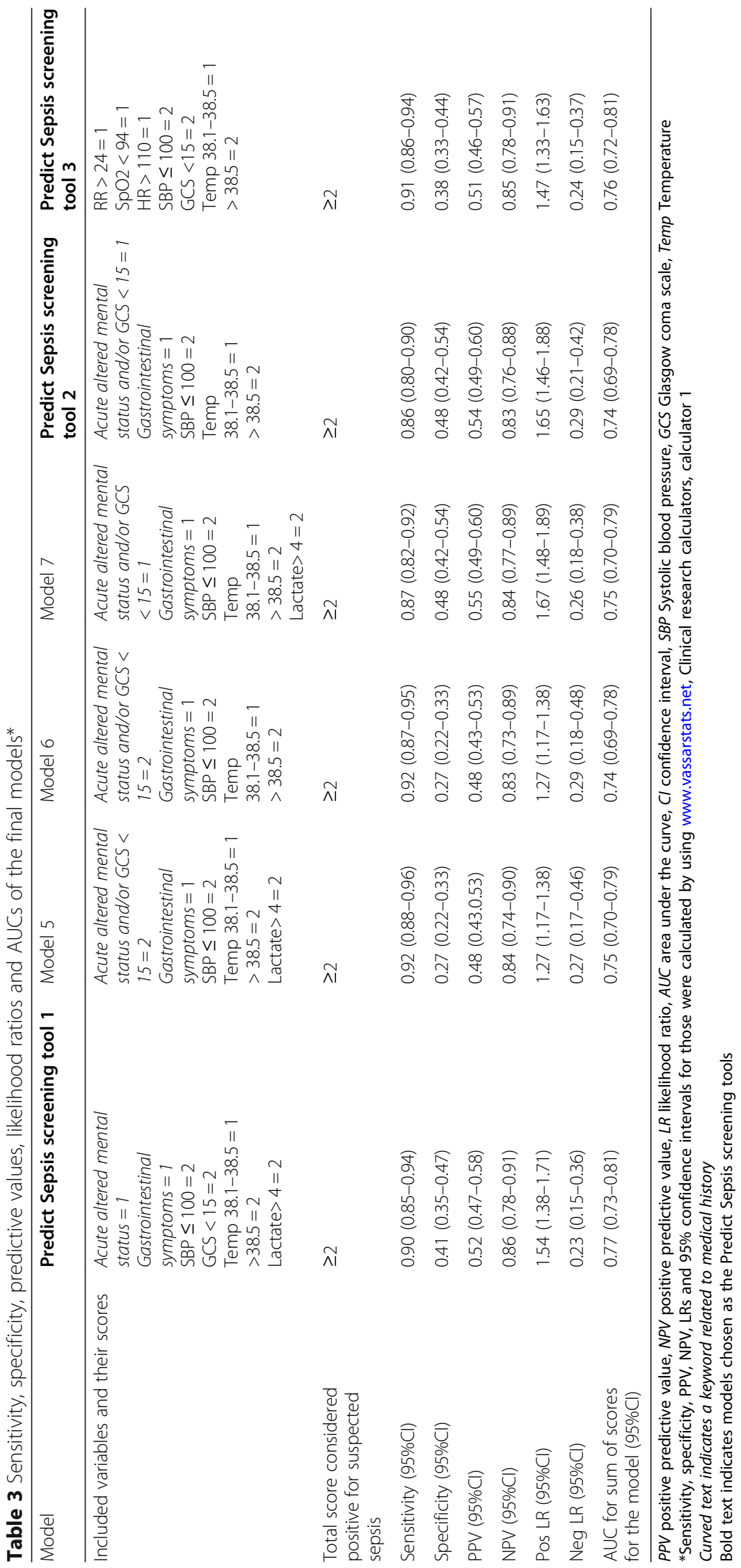




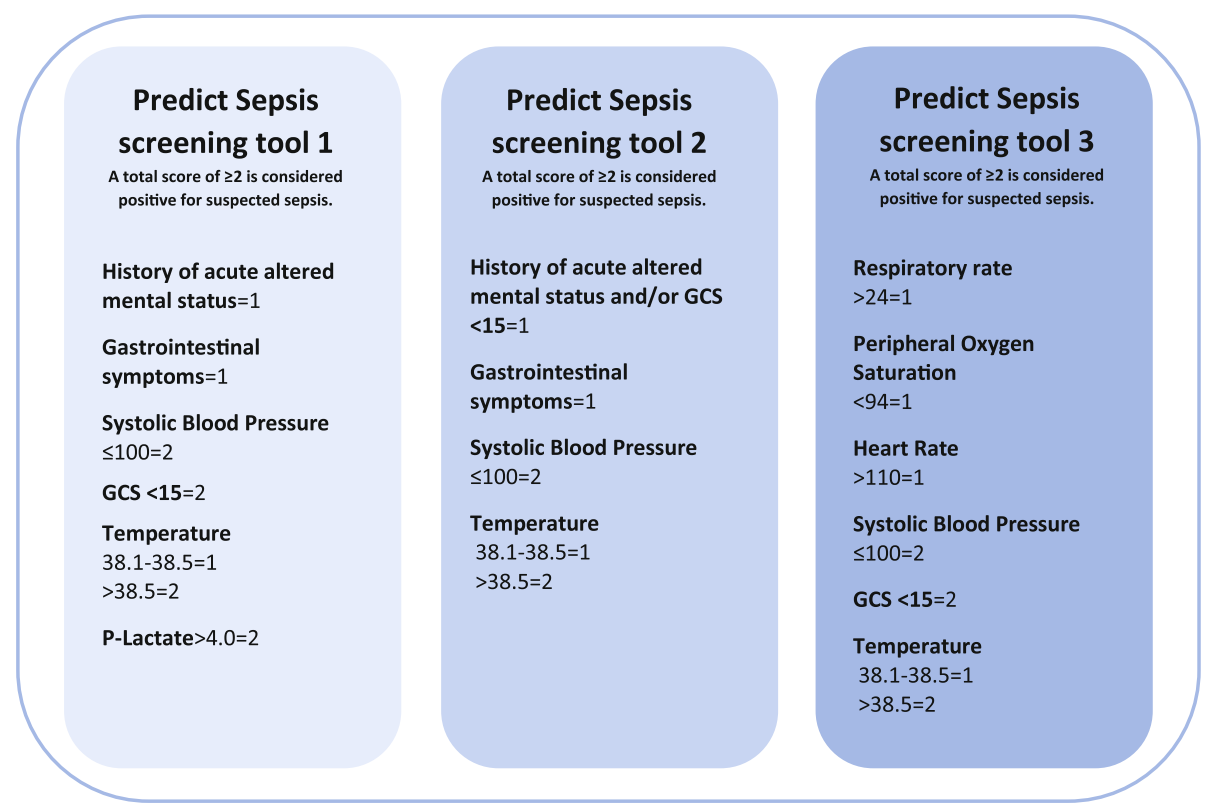

Fig. 4 The Predict Sepsis screening tools. The Predict Sepsis screening tools are developed for adult, non-trauma patients with suspected infection according to clinical judgment by ambulance personnel

adding symptom-variables and POC-tests in other study populations; i.e. not only among those with obvious signs of ongoing infection but rather among patients with non-specific presentations, as these patients are at a higher risk of not being identified as being septic.

The developed screening tools require external validation before clinical implementation and are applicable to adult, non-trauma ambulance patients with suspected infection according to clinical judgment by ambulance personnel.

\section{Conclusions}

Systolic blood pressure $\leq 100 \mathrm{mmHg}$, temperature $>38.5^{\circ} \mathrm{C}$, $\mathrm{GCS}<15$, lactate $>4 \mathrm{mmol} / \mathrm{L}$, gastrointestinal symptoms, and a history of acute altered mental status demonstrated the strongest association with sepsis. We present three screening tools to predict sepsis with similar sensitivity. The results indicated no noticeable increase of predictive ability by including symptom-variables and blood tests to a sepsis screening tool in the current study population. The major determining factor for which tool to recommend is the clinical setting where the tool is implemented, i.e. the availability of a computer-based alert system or not.

\section{Supplementary information}

Supplementary information accompanies this paper at https://doi.org/10. 1186/s13049-020-00745-6.

\section{Additional files 1-5.}

\section{Abbreviations}

AUC: Area Under the receiver operating Curve; GCS: Glasgow Coma Scale;

Cl: Confidence Interval; PPV: Positive Predictive Value; NPV: Negative
Predictive Value; NCT: National Clinical Registration; ED: Emergency Department; suPAR: soluble urokinase Plasminogen Activator Receptor; HBP: Heparin Binding Protein; POC: Point-Of-Care; CRF: Case Report Form; FRAPP: framtida IT-plattform för prehospital vård i Stockholms läns landsting; ICD: International Classification of Diseases; SOFA: Sequential Organ Failure Assessment; $\mathrm{PaO} 2$ : Partial pressure of Oxygen; FiO2: Fraction of inspired Oxygen; SPSS: Statistical Package for the Social Sciences; IQR: Interquartile Range; NEWS: National Early Warning Score; SIRS: Systemic Inflammatory Response Syndrome; ROC: Receiver Operating Characteristic; OR: Odds Ratio; CHAID: CHi-squared Automatic Interaction Detection; LR: Likelihood Ratio; STARD: Standards for the Reporting of Diagnostic accuracy studies

\section{Acknowledgements}

The authors would like to acknowledge first and foremost all the patients willing to participate, Samariten Ambulans AB Stockholm's ambulance personnel, including Torkel and Ulf Kanfjäll for including patients and for your understanding of the underlying incentive of the study, ViroGates Denmark for sponsoring suPAR-kits, Adam Linder, Lund University for information regarding HBP analyses, Daniel Eklund, Eva Särndahl, Örebro University for HBP analyses, Maaret Castren for valuable discussions regarding the selection of POC tests, Veronica Lindström and Veronica Vicente for testing the CRF, and Laerdal, FALCK Foundation, the Emergency Department of Södersjukhuset and Örebro University for funding.

\section{Authors' contributions}

UW was responsible for the literature search, study concept and design, information/education of ambulance personnel, data acquisition, analysis and interpretation of the data and the drafting of the manuscript. JS has contributed to the study concept and design, the drafting of the manuscript and to a critical revision of the manuscript for important scientific intellectual content. HP participated in the statistical analyses, had the principal responsibility for critical revision of these and contributed to the manuscript. LK has participated in the study conception and design, interpretation of the data, drafting of the manuscript and critical revision of the manuscript for important scientific intellectual content. In addition, LK contributed with administrative, financial support as well as supervision of the study. The author(s) read and approved the final manuscript.

\section{Funding}

This study was supported by grants from Laerdal, Falck Foundation, the Emergency Department of Södersjukhuset, Stockholm, and Örebro University. 
suPAR kits were provided by ViroGates, Denmark. The funders did not interfere in the interpretation of data, nor in writing the manuscript. Open access funding provided by Örebro University.

\section{Availability of data and materials}

The data that support the findings of this study are available from Karolinska Institutet Södersjukhuset but restrictions apply to the availability of these data, which were used under license for the current study, and so are not publicly available. Data are however available from the authors upon reasonable request and with permission of Karolinska Institutet Södersjukhuset

\section{Ethics approval and consent to participate}

The study received approval from the Stockholm Regional Ethical Review Board (reference number 2016/2001-31/2 and 2018/2202). Written consent was obtained from all participants.

\section{Consent for publication}

Not applicable.

\section{Competing interests}

All authors declare that they have no conflicting interests. UW and LK are members of the Swedish national working group for sepsis and LK is chair of the Swedish national working group for emergency medicine.

\section{Author details}

${ }^{1}$ Karolinska Institutet, Department of Clinical Science and Education, Söderssjukhuset, Sjukhusbacken 10, 11883 Stockholm, Sweden. ${ }^{2}$ Fisksätra Vårdcentral (Primary Health Care Center), Fisksätra torg 20, 13341 Saltsjöbaden, Sweden. ${ }^{3}$ Department of Medical Sciences, Uppsala University, Akademiska sjukhuset, 75185 Uppsala, Sweden. ${ }^{4}$ Department of Medical Sciences, Örebro University, Campus USÖ, Södra Grev Rosengatan 32, 70112 Örebro, Sweden.

Received: 21 March 2020 Accepted: 26 May 2020

Published online: 25 June 2020

\section{References}

1. Mouncey PR, Osborn TM, Power GS, Harrison DA, Sadique MZ, Grieve RD, et al. Trial of early, goal-directed resuscitation for septic shock. N Engl J Med. 2015:372(14):1301-11.

2. Yealy DM, Kellum JA, Huang DT, Barnato AE, Weissfeld LA, Pike F, et al. A randomized trial of protocol-based care for early septic shock. N Engl J Med. 2014;370(18):1683-93.

3. Peake SL, Delaney A, Bailey M, Bellomo R, Cameron PA, Cooper DJ, et al. Goal-directed resuscitation for patients with early septic shock. N Engl J Med. 2014:371(16):1496-506.

4. Wang HE, Weaver MD, Shapiro NI, Yealy DM. Opportunities for emergency medical services care of sepsis. Resuscitation. 2010:81(2):193-7.

5. Studnek JR, Artho MR, Garner CL Jr, Jones AE. The impact of emergency medical services on the ED care of severe sepsis. Am J Emerg Med. 2010.

6. Wallgren UM, Castren M, Svensson AE, Kurland L. Identification of adult septic patients in the prehospital setting: a comparison of two screening tools and clinical judgment. Eur J Emerg Med. 2014:21(4):260-5.

7. Wallgren UM, Antonsson VE, Castren MK, Kurland L. Longer time to antibiotics and higher mortality among septic patients with non-specfic presentations -a cross sectional study of emergency department patients indicating that a screening tool may improve identification. Scand J Trauma Resusc Emerg Med. 2016;24(1):1.

8. Bayer O, Schwarzkopf D, Stumme C, Stacke A, Hartog CS, Hohenstein C, et al. An early warning scoring system to identify septic patients in the Prehospital setting: the PRESEP score. Acad Emerg Med. 2015:22(7):868-71.

9. Polito CC, Isakov A, Yancey AH 2nd, Wilson DK, Anderson BA, Bloom I, et al. Prehospital recognition of severe sepsis: development and validation of a novel EMS screening tool. Am J Emerg Med. 2015:33(9):1119-25.

10. Robson W, Nutbeam T, Daniels R. Sepsis: a need for prehospital intervention? Emerg Med J. 2009;26(7):535-8.

11. Suffoletto B, Frisch A, Prabhu A, Kristan J, Guyette FX, Callaway CW. Prediction of serious infection during prehospital emergency care. Prehosp Emerg Care. 2011;15(3):325-30
12. Wallgren UM, Bohm KEM, Kurland L. Presentations of adult septic patients in the prehospital setting as recorded by emergency medical services: a mixed methods analysis. Scand J Trauma Resusc Emerg Med. 2017;25(1):23.

13. Huttunen $R$, Syrjanen J, Vuento $R$, Hurme M, Huhtala $H$, Laine J, et al. Plasma level of soluble urokinase-type plasminogen activator receptor as a predictor of disease severity and case fatality in patients with bacteraemia: a prospective cohort study. J Intern Med. 2011;270(1):32-40.

14. Linder A, Arnold R, Boyd JH, Zindovic M, Zindovic I, Lange A, et al. Heparin-binding protein measurement improves the prediction of severe infection with organ dysfunction in the emergency department. Crit Care Med. 2015;43(11):2378-86.

15. Ulf Kanfiäll CaSAA. Annual ambulance assignments Samariten Ambulans AB Stockholm: Samariten Ambulans AB; 2019.

16. Årsrapport 2017 Prehospitala verksamheter i SLL Sect. 4.1 and 6.2 (2017)

17. Folkmängd i riket, län och kommuner 31 mars 2018 och befolkningsförändringar 1 januari-31 mars 2018 [Internet]. Statistiska centralbyrån (SCB). 2018 [cited 23rd of March 2019]. Available from: https:// www.scb.se/hitta-statistik/statistik-efter-amne/befolkning/befolkningenssammansattning/befolkningsstatistik/pong/tabell-och-diagram/kvartals--ochhalvarsstatistik--kommun-lan-och-riket/kvartal-1-2018/.

18. Hälso och Sjukvårdsförvaltningen RS. Akutmottagningsbesök (exkl barnakut och psykakut): sll.se: Hälso och Sjukvårdsförvaltningen, Region Stockholm; 2018.

19. Charlson ME, Pompei $P$, Ales KL, Mackenzie CR. A new method of classifying prognostic comorbidity in longitudinal studies: development and validation. J Chronic Dis. 1987:40(5):373-83.

20. Singer M, Deutschman CS, Seymour CW, Shankar-Hari M, Annane D, Bauer $M$, et al. The third international consensus definitions for Sepsis and septic shock (Sepsis-3). JAMA. 2016;315(8):801-10.

21. Swedish Intensive Care registry (Svenska intensivvårdsregistret, SIR) [Web page]. 2015 [updated 2015-05-20 Available from: http://icuregswe.org/.

22. Beräkning av FiO2 vid syrgastillförsel med mask eller kateter [Internet]. Svenska intensivvårdsregsitret. 2018 [cited 2018-12-18]. Available from: https://www.icuregswe.org/globalassets/riktlinjer/sofa.pdf.

23. Peduzzi PCJ, Kemper E, Holford TR, Feinstein AR. A simulation study of the number of events per variable in logistic regression analysis. J Clin Epidemiol. 1996:49(12):1373-9.

24. Lowry R. VassarStats; Clinical Research Calculators, Calculator 1 www. vassarstats.net2019 [cited 2019. Available from: www.vassarstats.net

25. Physicians RCo. National Early Warning Score (NEWS) 2: Standardising the assessment of acute-illness severity in the NHS. Updated report of a working party. London: Royal College of Physicians; 2017.

26. Bone RC, Balk RA, Cerra FB, Dellinger RP, Fein AM, Knaus WA, et al. Definitions for sepsis and organ failure and guidelines for the use of innovative therapies in sepsis. The ACCP/SCCM consensus conference committee. American College of Chest Physicians/Society of Critical Care Medicine. Chest. 1992;101(6):1644-55.

27. Kass $\mathrm{G}$. An exploratory technique for investigating large quantitative of categorical data; 1980.

28. World Medical Association Declaration of Helsinki: ethical principles for medical research involving human subjects. JAMA. 2013;310(20):2191-4.

29. Bossuyt PM, Reitsma JB, Bruns DE, Gatsonis CA, Glasziou PP, Irwig L, et al. STARD 2015: an updated list of essential items for reporting diagnostic accuracy studies. Clin Chem. 2015;61(12):1446-52.

30. Singer AJ, Taylor M, Domingo A, Ghazipura S, Khorasonchi A, Thode HC Jr et al. Diagnostic characteristics of a clinical screening tool in combination with measuring bedside lactate level in emergency department patients with suspected sepsis. Acad Emerg Med. 2014;21(8):853-7.

31. Moran $J$, Santamaria J. Reconsidering lactate as a sepsis risk biomarker. PLoS One. 2017:12(10):e0185320.

32. Henriksen DP, Laursen CB, Jensen TG, Hallas J, Pedersen C, Lassen AT. Incidence rate of community-acquired sepsis among hospitalized acute medical patients-a population-based survey. Crit Care Med. 2015;43(1):13-21.

33. Seymour CW, Kennedy JN, Wang S, Chang CH, Elliott CF, Xu Z, et al. Derivation, Validation, and Potential Treatment Implications of Novel Clinical Phenotypes for Sepsis. JAMA. 2019.

34. Levy MM, Fink MP, Marshall JC, Abraham E, Angus D, Cook D, et al. 2001 SCCM/ESICM/ACCP/ATS/SIS international Sepsis definitions conference. Crit Care Med. 2003:31(4):1250-6.

\section{Publisher's Note}

Springer Nature remains neutral with regard to jurisdictional claims in published maps and institutional affiliations. 